\title{
Infrastructure Sharing for 5G Deployment: A Techno-Economic Analysis
}

\author{
https://doi.org/10.3991/ijim.v15i02.16749
}

Ibrahim Alhassan Gedel, Nnamdi I. Nwulu

University of Johannesburg, Johannesburg, South Africa

gedel.ibrahimegmail.com

\begin{abstract}
Fifth-generation wireless (5G) mobile communication technology has been classified as a high wireless standard that is capable of handling internet of things, machine-to-machine, and device-to-device communication. Consequently, there is a need to meet the very sensitive requirements of $5 \mathrm{G}$, which include high coverage density, high speed, high capacity and low end-to-end delay. Of crucial importance is 5G's passive infrastructure. This paper therefore presents a techno-economic analysis of the current telecommunication infrastructure, as well as investigating and determining the suitable passive infrastructure for $5 \mathrm{G}$ technology deployment. The paper outlines all the passive infrastructure elements and proposes a mathematical model to calculate the capital expenditure, operational expenditure, total cost of investment (TCI) or total cost of ownership (TCO) and net present value (NPV). Experiments are performed using market prices from the national communication authority, the mobile network operators and the tower company of Ghana. Furthermore, a sensitivity analysis is performed to identify the variables that increase the TCO or TCI, NPV and return on investment, and to propose the most economical passive infrastructure architecture for easy implementation of 5G technology in Ghana and Africa.
\end{abstract}

Keywords - 5G technology; Capital Expenditure; Operational Expenditure; Total Cost of Ownership; Infrastructure Sharing

\section{Introduction}

Mobile networks all over the world have experienced a tremendous increase in data demand due to technological advancements. The introduction of high definition video conference in real-time, online gaming and the introduction of applications such as device to device (D2D), Machine to Machine (M2M) and internet of things (IoT) (Bouras, Kollia, \& Papazois, 2017) (Elsaadany \& Soliman, 2017) have necessitated the mobile network operators $(\mathrm{MNO})$ to find a suitable technology that will meet the demand.

To meet these technological requirements, an advanced technology such as fifthgeneration wireless $(5 \mathrm{G})$ will meet the data requirements of the subscriber owing to its dense coverage, higher capacity and lower delays. The technology requires increasing numbers of base transceiver stations (BTS) (eNodeB, gNodeB) to meet the huge data demand and to provide services, such as $\mathrm{D} 2 \mathrm{D}$, IoT and M2M communications. The 
technology also requires investment in a large quantity of passive infrastructure (tower, power solution, cooling), which is very expensive. Most MNO around the world (including Ghana) own the passive infrastructure in use for the current $2 \mathrm{G}, 3 \mathrm{G}$ and $4 \mathrm{G}$ technology. Our theoretical framework is an extension of the existing approach of infrastructure sharing to economically deploy $5 \mathrm{G}$ technology.

A study by (Oughton \& Frias, 2018), shows that $5 \mathrm{G}$ infrastructure cost in Britain is very high and the economical way to reduce the cost of infrastructure is by infrastructure sharing and network virtualization (McKinsey \& Company, 2018) This paper will develop a Mathematical model that will be used to demonstrate how infrastructure sharing can be used to reduce the total cost of ownership of $5 \mathrm{G}$ network implementation.

This infrastructure demands huge capital and operational costs from the operators and destroys the environment because of the high number of towers. Reference (Teterin \& Hurley, 2014) observed that the high quantity of network infrastructure will increase the total energy consumption by 55 to $85 \%$ and $\mathrm{CO} 2$ emissions are predicted to increase by $6 \%$ by 2025 .

The passage of the Electronic Communications Act of 2008 in Ghana introduced an infrastructure sharing policy in a bid to mitigate the challenges associated with passive infrastructure (NCA Ghana Tests, 2018). This policy led to MNO and other service providers, such as television, radio and internet providers, renting space on towers in order to run these services.

The policy will only allow new towers to be built in areas where there is no tower and service quality is affected. Reference (Eal \& Boiardi, 2014) posits that telecommunication infrastructure sharing will allow independent tower companies to manage the infrastructure, while the MNO focus on providing the best telecom service with no capital expenditure (Capex) and very limited operational expenditure (Opex).

It will prevent network tower investment duplication and move the total cost of ownership (TCO) and the management of the towers to third parties. Most telecom operators have coverage obligations as part of their licensing contract with the government regulator and network sharing has become a smart, profitable choice to meet those obligations by extending network coverage using towers built by third parties.

Infrastructure sharing will enhance the deployment of $5 \mathrm{G}$ technologies and will help MNOs meet the dense coverage, high capacity and reduced latency requirements. Passive infrastructure sharing will spread the infrastructure expenditure of $5 \mathrm{G}$ implementation among multiple players, which will reduce cost and increase profitability.

The deployment of $5 \mathrm{G}$ will require many BS and the most economical way of achieving this is tower infrastructure sharing, which will allow the use of existing towers and minimise the need to build new towers. Some publications have considered economic analysis of 5G deployment. In refences (Smail \& Weijia, 2017) and (Christos Bouras, Vasileios Kokkinos, Anastasia Kollia, 2017), (Bargarai, Abdulazeez, Tiryaki, \& Zeebaree, 2020) the techno-economic analysis of small cell and a distributed antenna system (DAS) was examined using various financial models.

The models included Capex, Opex and implementation expenditure based on the net present value (NPV) and cell area. In reference (Bouras et al., 2017), the TCO for a DAS is defined as the sum of Capex, Opex and implementation costs. In reference (Osei-owusu \& Henten, 2017), a qualitative and quantitative study is reported on 
telecom infrastructure sharing in Ghana. The result shows that the policy has reduced tower duplication and eliminated TCO to MNO. The paper shows that the QoS offered by the tower company was commendable.

Reference [10](Bhardwaj, 2013) reported a study on the growth and future prospect of the fresh business model of infrastructure sharing in the Indian telecom industry. The paper described various forms of infrastructure sharing: active, passive and backhaul sharing. The paper shows that passive infrastructure sharing will reduce Capex by $40 \%$ and Opex by $60 \%$. The paper adds that MNO receive significant cost reduction, improved uptime, easy network expansion and improved QoS. Reference (Akanfe, 2015; Bhardwaj, 2013; Derban, 2011) is a study conducted in Benue State, arguing that infrastructure sharing led to cost optimization and revenue generation. The paper added that infrastructure sharing will result in a rapid rollout of network coverage and increased capacity, with a $50 \%$ reduction in investment costs.

The paper stressed that techno-economic evaluation is the modelling and analysis of the customer demand, operational cost, and revenue, technology rollout etc. The authors also define the network cost estimate as a function of customer demand and topographical distribution. In reference (Bouras et al., 2017), a cost model for DAS and small cell was presented. Furthermore, a sensitivity analysis (SA) was done on the allocated bandwidth, running cost and predicted interest rate. Findings show that TCO increases proportionally to the small cells, but site deployment cost and bandwidth have a great effect on the TCO of the DAS. In references (Smail \& Weijia, 2017) and (Thabane et al., 2013), a mathematical model for price, volume elasticity and price elasticity was presented. The paper also presented a model for a future number of subscribers, making the assumption that an increase in the population is directly proportional to subscriber growth.

Although a lot of work on a techno-economic model and SA of essential variables, as well as tower sharing, has been presented in literature, the authors do not consider telecom infrastructure sharing in $5 \mathrm{G}$, techno-economic model for $5 \mathrm{G}$ infrastructure sharing and passive infrastructure element for 5G technology. References (Smail \& Weijia, 2017), (Christos Bouras, Vasileios Kokkinos, Anastasia Kollia, 2017), (Bouras, Kokkalis, Kollia, \& Papazois, 2018b), (Bouras, Kokkinos, \& Papazois, 2014), (Bouras et al., 2018b), (Oughton \& Frias, 2018) and (McKinsey \& Company, 2018) present techno-economic models and SA for DAS, multi-input-multi-output (MIMO), macrocell and small cell, but the model presented does not take into account the effects of inflation, interest rate, tower height, number of MNO per tower, ROI and NPV on investments in $5 \mathrm{G}$ coupled with passive infrastructure sharing. The key contributions of this study are highlighted below:

a) All the passive infrastructure elements for 5G technology implementation are outlined.

b) A mathematical model for Capex, Opex, TCO and NPV will be presented for 5G infrastructure sharing.

c) This study will investigate the Capex, Opex, the TCO and the NPV and return on investment (ROI) for $40 \mathrm{~m}, 45 \mathrm{~m}$ and $60 \mathrm{~m}$ towers with and without hybrid activation. 
d) An SA was performed on a $40 \mathrm{~m}, 45 \mathrm{~m}$, and $60 \mathrm{~m}$ tower using the interest rate of $2.5 \%$ to $9.5 \%$ as variable, to investigate the effect of interest rate on the Capex, Opex, total cost of investment (TCI) or TCO.

e) SA was again performed on a $40 \mathrm{~m}, 45 \mathrm{~m}$ and $60 \mathrm{~m}$ tower using the number of MNO and the variable, one to six $\mathrm{MNO}$ were used to investigate the effect of one, two, tree, four, five or six MNO on the Capex, Opex, TCI or TCO and the ROI.

\section{Passive Infrastructure Sharing Elements}

Passive infrastructure sharing is non-electronic infrastructure sharing at a cell site. This occurs where energy, a tower and space are shared by more than one MNO. There is also electronic sharing, which includes antenna, radio link, fibre link and BTSs. Because of the significant effect of the network infrastructure, the Electronic Communications Act of 2008 of Ghana introduced an infrastructure sharing policy in 2008 (Eal $\&$ Boiardi, 2014). Some of its stipulations are the height of the tower, the $\mathrm{CO} 2$ emission and the reduction of the TCO. Passive infrastructure being adopted worldwide (Namisiko, Sakwa, \& Waweru, 2015), (Levine, 2012) includes communications towers, power supply, generators, batteries, power hybrid, solar hybrid solutions for fuel optimisation and solar air-conditioners, fire extinguishers and BTS shelters.

\subsection{Telecommunication towers}

A telecommunication tower can be described as a set of mechanical structures that can vary in height, depending on the area in which they are located and their purpose. Telecom towers are used to connect mobile networks, television antennas and radio broadcasting. Telecom towers are used to enable communication among people. Communication through networking requires elevated antennas to transmit and receive radio communications effectively. The various types of towers include lattice towers, stealth towers, guyed towers and monopole towers and come in $30 \mathrm{~m}, 40 \mathrm{~m}, 50 \mathrm{~m}, 60 \mathrm{~m}$ and $70 \mathrm{~m}$ height. Tower installation can be rooftop- (Derban, 2011)or ground-based. The major companies include AT\&T, American Tower Corporation, Helios Towers Africa, Bharti Infratel, China Tower Corporation, SBA Communications, Crown Castle International Corporation and T-Mobile Towers.

\subsection{Diesel generators}

A brief power outage in the telecommunications industry can be costly, especially when sites' service level agreement (SLA) between the tower company and the MNO are on $\mathrm{AC}$ power. Again, telecom subscribers are not supposed to experience any call drops or poor QoS due to power outage. It is therefore very important to have a backup power generator for constant and reliable operation. Telecom voice, data, or cloud services are supposed to be available constantly and grid failure must not result in any network failure. Generators play a key role on cell sites during grid power failure as backup power supply. Generators have long been a backbone in the 
telecommunications industry. Areas without grid power are powered with generators to extend the coverage to these areas. Telecom backup power generator units are automated to ensure an instantaneous starting time and eliminate the need for manually starting the unit. Diesel generators must be reliable, safe, efficient and affordable. The type of diesel generators commonly used in the telecom industry in Africa are the Perkins, Genlogics, Cummins and Caterpillar generators.

\subsection{Solar energy system}

One of the most useful renewable energy sources is the sun. Photovoltaic (PV) technology is used in solar energy generation, with the principle of operation based on the conversion of sunlight into electricity. For large-scale solar energy generation, an array of solar PV cells is connected in series to increase the capacity. In a wireless system such as the Global System for Mobile Communications or Wideband Code Division Multiple Access, cell sites located in a remote area where the grid is not available use solar power. This is to reduce the high cost of fuel and maintenance on a diesel generator, air pollution, environmental pollution and $\mathrm{CO} 2$ emissions. In developing countries, most $\mathrm{MNO}$ are forced by the regulators to extend coverage to remote areas, as revenues are very low. Operational and maintenance costs cannot be covered by generated revenue, so MNO make use of a solar solution.

PV energy combined with a deep cycle battery can store power in the battery at times of high solar intensity and the saved battery power will power the cell site when there is no sunlight.

\subsection{Hybrid power system}

Hybrid power is the combination of two or more energy sources connected to the same load. One energy source is prioritised to run based on cost; in most cases the grid is the primary source. The commercial power is made to charge the deep cycle batteries through an AC-DC converter to store an amount of DC power. An intelligent controller is placed to control energy usage. The controller prioritises the deep cycle battery to supply $\mathrm{DC}$ power to the equipment when $\mathrm{AC}$ power fails. The diesel generator starts to power the equipment and recharge the deep cycle battery when the batteries discharge below the set threshold. This solution reduces the hours of running of the generator by $60 \%$, and environmental pollution by $5 \%$.

\subsection{Infrastructure sharing on 5G LTE}

$5 \mathrm{G}$ technology is expected to have denser coverage, high capacity, lower latency and a higher throughput requirement. To achieve the $5 \mathrm{G}$ requirement, a higher frequency band greater than both $3 \mathrm{G}$ and $4 \mathrm{G}$ is needed; this is between $3.5 \mathrm{GHz}$ and $7.5 \mathrm{GHZ}$. This higher frequency will result in a short wavelength. To meet the coverage requirement, many cell sites need to be deployed both indoors and outdoors. Based on the frequency of $5 \mathrm{G}, \mathrm{MNO}$ will need to invest heavily in infrastructure and the cheaper way is by infrastructure sharing. 
$5 \mathrm{G}$ infrastructure sharing is of two types, electronic infrastructure sharing and nonelectronic infrastructure sharing. Electronic sharing in 5G technology comprises the sharing of radio BSs (new radio), antenna sharing and transceivers. A centralised data centre is the new $5 \mathrm{G}$ core that is designed to be shared with different $\mathrm{MNO}$ on different continents with ultra-reliable low-latency communication (URLLC) (Alwraikat, 2015). The sharing of the core network is possible because of the introduction of network function virtualisation and software-defined networking in 5G technology. URLLC can be achieved by the implementation of the multi-access computing cloud data centre where application and processing of information are undertaken closer to the user. $5 \mathrm{G}$ technology is quite unique; the ownership of the core will be very expensive because of the number of different solutions it can offer. The core will be shared strictly; this is the best and most cost-effective way $5 \mathrm{G}$ can be implemented. This study is limited to the non-electronic sharing of $5 \mathrm{G}$ infrastructure or passive infrastructure sharing. Passive sharing includes sharing of power (AC/DC) tower space and cooling systems if sites are indoors.

The towers are normally built and managed by the tower companies. Management will include ensuring that the power meets the set SLA in Ghana, namely $99.95 \%$ uptime. MNO will install radio equipment including remote radio units (RRUs), or new radio, the baseband unit (BBU), the antenna, fibre optics as fronthaul, and the backhaul network (internet protocol network).

\section{Economic Mathematical Modelling}

Economic models are tools used to analyse the risk in financial investment in various businesses. The models include the present value, the NPV, profitability index and internal rate of return, which are used for analysis of large projects. The project is good only if the present value is greater than the initial cost of the investment. The profitability index must be greater than one. The economic model depends on the Capex, Opex and the TCI.

\subsection{Mathematical model formulation}

In this section, we develop an improved economic model for an annual repeating payment for the telecom infrastructure and the TCO. The new model will be an improvement on the models in equations 1, 2, and 3 (Smail \& Weijia, 2017), (Christos Bouras, Vasileios Kokkinos, Anastasia Kollia, 2017), (Bouras et al., 2018b), (Bouras et al., 2014).

$$
A=P \frac{r(1+r)^{n}}{(1+r)^{n}-1}
$$




$$
\begin{gathered}
A=\frac{i}{1-(1+i)^{-n}} C \\
C_{\text {macro }}^{T C O}=\left(1+f_{m}\right) N\left(C_{e N B}+C_{E P C}\right) \frac{r(1+r)^{n}}{(1+r)^{n-1}} \\
+N c_{s t}+f_{B W} B W
\end{gathered}
$$

Equation (1) is a repeating payment model where $A$ is the annual settlement, $r$ symbolises the interest rate, $P$ the individual present value and $n$ the years of repayment. Equation (2) $A$ is the annual repayment, $C$ is the total present value, $i$ is the interest rate and $n$ is the number of years of repayment. Equation (3) is the TCO for a macro cell where $N$ is the number of eNodeB, $C_{e N B}$ is the capital cost for a single BS, $C_{E P C}$ is the capital cost of deploying the core network of a single $e N B . f_{B W}$ is the backhaul bandwidth expressed in $€ / \mathrm{Gbps},{ }^{s t}$ is site costs apart from maintenance cost, cost of backhaul BW for a site's interconnection and $f_{m}$ site maintenance costs. Equations 1 and 2 both have a limitation of repayment always being made to the investor at the end of the investment; there is no pre-instalment. The parameter used in this model does not clearly consider this passive infrastructure cost. The tower company or the MNO has no assurance of payment; investment using this model is risky if the MNO defaults on payment. The model used will require a longer repayment period of at least 10 years. The model does not take into account the time value for money; tower companies will

lose owing to interest rate and inflation fluctuation. Equation 3 is the TCO for a macro-cell, which does not take into consideration the infrastructure capital cost and the infrastructure operational cost. In equation $3 \mathrm{TCO}$ does not consider if the tower infrastructure is owned by the MNO or rented. The model does not factor in the height of the tower, which is a principal cost element in tower construction. The limitations of the model above show many gaps in the result that will have to be addressed in the proposed model.

\subsection{Conventional model formulation}

The aim of the study is to develop a risk-free economic model that will mitigate all the limitations of the models used in (Bouras et al., 2014), (Smail \& Weijia, 2017), (Bouras, Kokkalis, Kollia, \& Papazois, 2018a), (Bouras et al., 2018b), (Bouras et al., 2017). The new model will take into account all the parameters for base station (BS) (new 5G radio), fronthaul, RRUs, and antenna. Capital cost and operational cost will be modelled with respect to the tower height. The model is annuity due, meaning 
payment for the investment will be done before sharing; this gives the advantage to the tower company.

The limitation of the model in equations 1 and 2 on time value interest rate drops and infltions being addressed because the new model is $(1+m)$ times the previous model. The other advantage of this model is that the TCO value will be $(1+m)$ times the previous model, which makes it more robust and risk-free for tower and MNO companies. The initial cost of investment is greater than the NPV, which shows a good NPV and ROI. The initial capital investment will include tower supply, land acquisition, AC power, backup power solution, hybrid solution (power hybrid or solar hybrid) and generator, air-conditioning, rectifier systems or DC power plant, fibre infrastructure, building and cost of installation. The initial operational investment will also include site management cost, security management cost, energy cost (fuel, commercial power charges) and other cost such as salaries, office and apartment rent. The capital and operational cost model will be used to model the total cost of ownership or the initial cost of investment and finally, an NPV model will be developed for the tower company. The study will outline all the passive infrastructure elements for $5 \mathrm{G}$ implementation. A mathematical model for Capex, Opex and TCO will be presented for $5 \mathrm{G}$ infrastructure sharing. The paper will also present a mathematical model for the NPV. This study will investigate the Capex, Opex, TCO and NPV with cost data from the MNO, Tower Company of Ghana and National Communication Authority. Finally, an SA (Thabane et al., 2013) is used to assess the effect and influence of a key variable element of the $5 \mathrm{G}$ passive infrastructure sharing.

Referring to equations 1 and 2

$$
C_{p}=C_{i}(1+m)\left(\frac{m(1+m)^{n}}{(1+m)^{n}-1}\right)
$$

Suppose $C_{i n v}$ is the initial capital of investments, $m$ is the interest for the cost of capital and $C_{c x m c}$ is the repayment amount, then

$$
C_{c x m c}=C_{I n v}(1+m)\left(\frac{m(1+m)^{n}}{(1+m)^{n}-1}\right)
$$

\subsection{Capex for telecom tower construction}

Capex is the amount of money invested in the deployment of the new infrastructure [19] in the telecom tower deployment. The initial cost includes the land acquisition, tower, generator, air-conditioning, rectifier systems or DC power plant, hybrid solution (power hybrid or solar hybrid), building and cost of installation. If CTW is the cost of 
the tower and freight, CDCP is the DC power plant, Chyb is the cost of the hybrid, $\mathrm{CDG}$ is the cost of the diesel generator for this analysis, which we regard as $20 \mathrm{KVA}$, Cord is the cost of installation and others (land acquisition, permit acquisition, then CINVT is the initial capital for one tower.

$$
C_{I n v T}=\left(C_{T W}+C_{D G}+C_{D C P}+C_{h y b}+C_{o r d}\right)
$$

If $N$ is the total number towers this

$$
C_{\text {InvT }}=N\left(C_{T W}+C_{D G}+C_{D C P}+C_{h y b}+C_{o r d}\right)
$$

By substituting equation (7) into (5), the Capex of towers is given by

$$
C_{c x m c}=(1+m)\left(\frac{m(1+m)^{n}}{(1+m)^{n}-1}\right) N\left(\begin{array}{l}
C_{T W}+C_{D G} \\
+C_{D C P}+C_{h y b}+C_{o r d}
\end{array}\right)
$$

\subsection{Opex for telecom infrastructure}

Opex is the amount of money invested in the costs of the day-to-day operation of the system, depending on the type of operation. The operational cost for telecom infrastructure comprises the site management cost, security management cost, energy cost and other cost such as salaries, office and apartment rent.

From equations 1 and 2, the Opex can be remodelled as

$$
C_{\text {oxmc }}=C_{\text {oxInv }}(1+m)\left(\frac{m(1+m)^{n}}{(1+m)^{n}-1}\right)
$$

where $C_{\text {oxmc }}$ is the total operational cost, $C_{\text {oxinv }}$ is the total actual initial capital, $\mathrm{m}$ is the cost of operational capital and $\mathrm{n}$ is the number of years to repay it. If $C_{S M}$ is the site management charge, which includes preventive maintenance, site day-to-day activities etc., $C_{s s}$ is the site security management and $C_{E C}$ is the site energy consumption cost, $C_{o d}$ is the other cost and $N$ is the number of towers to be maintained. Then $C_{\text {oxinv }}$ is the sum of all the

$$
C_{\text {oxInv }}=N\left(C_{S M}+C_{S S}+C_{E C}+C_{o d}\right)
$$

By substituting equation (10) into (9) 


$$
C_{\text {oxmc }}=(1+m)\left(\frac{m(1+m)^{n}}{(1+m)^{n}-1}\right) N\left(\begin{array}{l}
C_{S M}+C_{S S} \\
+C_{E C}+C_{o d}
\end{array}\right)
$$

\subsection{Total cost of investments}

The TCO or TCI is an evaluation that places a single value on the complete lifespan of a capital purchase. (Knoll, Staufer, \& Knoll, 2012) It is a financial estimate that helps consumers and owners determine the direct and indirect costs of a product or service. It is also defined as the sum of the operational cost and the capital cost and emphasises the difference between buying price and future cost. TCI evaluation can help make critical agreement vs. purchase comparisons. It concerns vendor selection, prioritisation of capital acquisition and overall corporate budgeting.

$$
T_{C T_{T O}}=C_{C X M C T}+C_{O X M C}
$$

Summing equation (8) and (11) in (12) yields

factorization equation (12)

$$
\begin{aligned}
& T_{C T_{T O}}=(1+m)\left(\frac{m(1+m)^{n}-1}{m}\right) N\left(\begin{array}{l}
C_{T W}+C_{D G} \\
+C_{D C P}+C_{h y b}+C_{o r d}
\end{array}\right) \\
& +(1+m)\left(\frac{m(1+m)^{n}-1}{m}\right) N\left(C_{S M}+C_{S S}+C_{E C}\right) \\
& T_{C T_{T O}}=(1+m)\left(\frac{m(1+m)^{n}-1}{m}\right) N\left\{\begin{array}{l}
N\left(\begin{array}{l}
C_{T W}+C_{D G} \\
+C_{D C P}+C_{h y b}+C_{o r d}
\end{array}\right) \\
+\left(C_{S M}+C_{S S}+C_{E C}\right)
\end{array}\right)
\end{aligned}
$$

The above model will calculate the TCI for the construction of a telecom tower, under all conditions. The model considers the height, the type of energy solutions and all possible operational cost not considered in all the reviews done.

\subsection{Net present value}

Risk and cash inflows in capital budgeting is rare. Risk in capital budgeting is the degree of variability of cash flows. This risk actually results from the interaction of these underlying variables (Gitman \& Zutter, 2013). Therefore, to assess the risk of proposed capital expenditure, the analyst needs to evaluate the probability that the cash inflows will be large enough to produce a positive NPV. The telecom industry is 
undergoing high investment, requiring a financial model that will bridge the technology and mitigate the risk. This risk can be eliminated:

$$
N P V_{M C T}^{r}=\frac{C_{\mathrm{Rent}}}{r}\left(1-\frac{1}{(1+r)^{n}}\right)-T_{C_{\mathrm{Im} v}}
$$

Equation 15 can be used to calculate the NPV of the investment over a period of

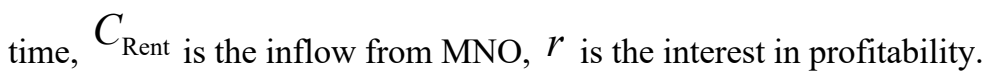

\section{$4 \quad$ Model Verification}

$5 \mathrm{G}$ technology will require a great deal of NR to be deployed to yield dense coverage, high capacity, high throughput and ultra- reliable low-latency communication. 5G will require shorter intersite distances (ISD), meaning MNOs will deploy many more sites than in 4G. Both old $4 \mathrm{G}$ and $3 \mathrm{G}$ of $1 \mathrm{GHz}$ to $2.6 \mathrm{GHz}$ will be required for high coverage, as well as a new high band spectrum between $3.5 \mathrm{GHz}$ to $40 \mathrm{GHz}$ for high capacity. The deployment will require the installation of RRU (4T4R, 8T8R, 16T16R, 16T16R, 32T32R), with a massive MIMO antenna and fronthaul (fibre optics) on the tower. Depending on the architecture, BBU will be installed on site and on some sites, there will be only RRU and an antenna connected to a centralised BBU through a fronthaul. Based on the needs for $5 \mathrm{G}$ technology, the cheapest and easiest way of deploying $5 \mathrm{G}$ technology is by network sharing; it will be very difficult for MNO to meet the ISD, since the cost of the infrastructure will be very huge. In this section testing of the model will use MTN Ghana in the Tema metropolitan area of $565 \mathrm{~km} 2$ (Norty, 2013)(NCA Ghana Tests, 2018)(National Communication Authority, 2017), which has a population of 292773 , of which 47.8 percent are male and 52.2 percent female. The population of the Tema metropolis is entirely urban. The total stock of houses is 40956 . We will verify the economic performance based on the ISD (Yunas, Ansari, \& Valkama, 2016) (Joseph, 2013) of $1732 \mathrm{~m}, 866 \mathrm{~m}$ and $433 \mathrm{~m}$. The total number of towers will be estimated per ISD, Capex, Opex and TCO.

Finally, an SA (Thabane et al., 2013) is used to assess the influence of a key variable element of the $5 \mathrm{G}$ passive infrastructure sharing, namely the effect of the interest rate on the Capex, Opex, TCO or TCI on a $40 \mathrm{~m}, 45 \mathrm{~m}, 60 \mathrm{~m}$ and $80 \mathrm{~m}$ tower. A comparison will be made of Capex, Opex, TCO, NPV, and ROI sharing of a $40 \mathrm{~m}, 45 \mathrm{~m}$ and $60 \mathrm{~m}$ tower with six mobile network operators with and without hybrid technology activated. Finally, we will be presenting to the TowerCO and MNO the most economical infrastructure suitable for the implementation of 5G technology in Ghana and Africa. 
Table 1. TCO cost parameters and system variables

\begin{tabular}{|c|c|c|}
\hline Parameter & Cost Descriptions & Values \\
\hline $\mathrm{TH}$ & Tower height & $40 \mathrm{~m}, 45 \mathrm{~m}, 60 \mathrm{~m}$ \\
\hline$C_{\text {ord }}$ & $\begin{array}{l}\text { Site acquisition, TSS, materials and ser- } \\
\text { vices }\end{array}$ & $\$ 40840, \$ 46857, \$ 47092, \$ 62495$ \\
\hline$C_{T W}$ & Tower material & $\begin{array}{c}\$ 13616, \$ 14646, \$ 14746, \$ 24189, \$ 37 \\
750 .\end{array}$ \\
\hline CDG & Genset and ATS & $\$ 9168, \$ 10000, \$ 12000, \$ 13168$ \\
\hline $\mathrm{CDCP}$ & SMPS and rectifiers & $\$ 3346.55$ \\
\hline CBatt & Batteries - 600 Ah & $\$ 4173$ \\
\hline$C_{s s}$ & Monitoring and security & $\$ 5450$ \\
\hline $\mathrm{Ce}$ & Grid connection & $\$ 4000$ \\
\hline$m$ & Interest rate & $2.5,3.5,4.5,5.5,6.5,7.5,8.5,9.5$ \\
\hline$N$ & MNO & 6 \\
\hline$C_{h y b}$ & Hybrid Activation & $\$ 8346$ \\
\hline $\mathrm{n}$ & Years plan for the site repayment & 6 \\
\hline
\end{tabular}

\section{$5 \quad$ Result of Simulation}

Table 2. Capex, Opex, TCO, NPV, ROI for $40 \mathrm{~m}$ tower, $7.5 \%$ interest rate.

\begin{tabular}{|c|c|c|c|c|}
\hline Capex (k\$) & Opex(k\$) & TCO(k\$) & NPV (k\$) & ROI (k\$) \\
\hline 17.17 & 3.20 & 20.36 & 12.00 & -8.36 \\
\hline 17.17 & 4.36 & 21.53 & 27.84 & 6.31 \\
\hline 17.17 & 5.53 & 22.70 & 43.68 & 20.98 \\
\hline 18.07 & 6.69 & 24.76 & 59.51 & 34.75 \\
\hline 18.07 & 7.86 & 25.93 & 75.35 & 49.42 \\
\hline 18.07 & 9.03 & 27.10 & 91.18 & 64.08 \\
\hline
\end{tabular}

Table 3. Result Capex, Opex, TCO, NPV, ROI for $40 \mathrm{~m}$ tower, $7.5 \%$ interest rate, hybrid activated.

\begin{tabular}{|c|c|c|c|c|}
\hline Capex (k\$) & Opex (k\$) & TCO (k\$) & NPV (k\$) & ROI (k\$) \\
\hline 17.17 & 1.73 & 18.89 & 12.00 & -6.89 \\
\hline 17.17 & 2.62 & 19.79 & 27.84 & 8.05 \\
\hline 18.14 & 3.70 & 21.85 & 43.68 & 21.83 \\
\hline 18.96 & 14.55 & 23.51 & 59.51 & 36.00 \\
\hline 18.96 & 5.66 & 24.62 & 75.35 & 50.73 \\
\hline 18.96 & 6.62 & 25.58 & 91.18 & 65.61 \\
\hline
\end{tabular}


Table 4. Capex, Opex, TCO, NPV, ROI for $45 \mathrm{~m}$ tower, $7.5 \%$ interest rate

\begin{tabular}{|c|c|c|c|c|}
\hline Capex (k\$) & Opex (k\$) & TCO (k\$) & NPV (k\$) & ROI (k\$) \\
\hline 18.67 & 3.23 & 21.89 & 12.00 & -9.89 \\
\hline 18.67 & 4.39 & 23.06 & 27.84 & 4.78 \\
\hline 18.67 & 5.56 & 24.23 & 43.68 & 19.45 \\
\hline 19.57 & 6.72 & 26.29 & 59.51 & 33.22 \\
\hline 19.57 & 7.89 & 27.46 & 75.35 & 47.89 \\
\hline 19.57 & 9.06 & 28.63 & 91.18 & 62.56 \\
\hline
\end{tabular}

Table 5. Capex, Opex, TCO, NPV, ROI for $45 \mathrm{~m}$ tower, $7.5 \%$ interest rate, hybrid activated.

\begin{tabular}{|c|c|c|c|c|}
\hline Capex (k\$) & Opex (k\$) & TCO (k\$) & NPV (k\$) & ROI (k\$) \\
\hline 18.67 & 1.90 & 20.57 & 12.00 & -8.57 \\
\hline 18.67 & 2.69 & 21.35 & 27.84 & 6.48 \\
\hline 18.75 & 3.84 & 22.59 & 43.68 & 21.09 \\
\hline 20.46 & 4.57 & 25.03 & 59.51 & 34.48 \\
\hline 20.46 & 5.68 & 26.14 & 75.35 & 49.21 \\
\hline 20.46 & 6.64 & 27.10 & 91.18 & 64.08 \\
\hline
\end{tabular}

Table 6. Result Capex, Opex, TCO, NPV, ROI, for $60 \mathrm{~m}$ tower, $7.5 \%$ interest rate

\begin{tabular}{|c|c|c|c|c|}
\hline Capex (k\$) & Opex(k\$) & TCO (k\$) & NPV (k\$) & ROI (k\$) \\
\hline 20.75 & 3.48 & 24.23 & 12.00 & -12.22 \\
\hline 20.75 & 4.64 & 25.39 & 27.84 & 2.45 \\
\hline 20.75 & 5.81 & 26.56 & 43.68 & 17.12 \\
\hline 21.65 & 6.98 & 28.63 & 59.51 & 30.88 \\
\hline 21.65 & 8.14 & 29.79 & 75.35 & 45.55 \\
\hline 21.65 & 9.31 & 30.96 & 91.18 & 60.22 \\
\hline
\end{tabular}

Table 7. Result Capex, Opex, TCO for $60 \mathrm{~m}$ tower, $7.5 \%$ interest rate, hybrid activated.

\begin{tabular}{|c|c|c|c|c|}
\hline Capex (k\$) & Opex (k\$) & TCO (k\$) & NPV (k\$) & ROI (k\$) \\
\hline 20.75 & 1.91 & 22.66 & 12.00 & -10.66 \\
\hline 20.75 & 2.79 & 23.54 & 27.84 & 4.30 \\
\hline 20.75 & 3.78 & 24.52 & 43.68 & 19.15 \\
\hline 21.65 & 4.60 & 26.25 & 59.51 & 33.26 \\
\hline 21.65 & 6.03 & 27.68 & 75.35 & 47.67 \\
\hline 21.65 & 7.04 & 28.69 & 91.18 & 62.49 \\
\hline
\end{tabular}

\subsection{Discussion of Result}

The objective of the paper is to analyse and find the most efficient and cost-effective infrastructure solution for the $5 \mathrm{G}$ technology implementation in Ghana and how to fuse this into the current architecture. The paper outlines all passive infrastructure element for $5 \mathrm{G}$ deployment, a mathematical model for Capex, Opex, and TCO was also presented for infrastructure sharing and Model was tested. Sensitivity analysis (SA) was 
performed on $40 \mathrm{~m}, 45 \mathrm{~m}$, and $60 \mathrm{~m}$ tower using key cost variables (interest rate, number of MNO, Hybrid Activation).

Tables 2 and 3 are the simulation result for a $40 \mathrm{~m}$ tower. The outcome shows the Capex, Opex, TCO, NPV and ROI. The study compared TCO, NPV and ROI when the backup power for a BS is only a diesel generator and when a diesel generator and hybrid system are used as backup, the genset kicks in after a hybrid time. The simulation uses an investment period of six years. Annual repayment in this case will be received at the start of the project. An annual TCO was calculated based on capital and operational cost. The NPV is based on the revenue realised from the tower and the ROI is the difference between the TCO and NPV. The study shows that Capex is the same for the first three MNO, but operational cost is increased by $32.4 \%$ for any additional MNO. Capital cost will rise by $5 \%$ if the number of MNO increases from three to six and operational cost will increase by $13.96 \%$. The result shows a negative annual ROI when only one MNO is using the towers and the period of repayment will be longer. Hybrid implementation will increase Capex by $3.6 \%$ and will cut Opex by $32.1 \%$. TCO will increase by $5.6 \%$ and ROI will increase by $4.95 \%$. Tables 4 and 5 show the Capex, Opex, TCO, NPV and ROI of a $45 \mathrm{~m}$ tower, the result shows that there is an increase of $2 \%$ in the Capex when a hybrid system is implemented but there is an operational cost saving of $31 \%$, a $6 \%$ cut in the total cost of ownership and a $6 \%$ increase in ROI.

The results of the $60 \mathrm{~m}$ tower without and with hybrid activation are presented in tables 6 and 7. The simulation shows that when hybrid operation is activated, operational cost is cut by $32 \%$, TCO is reduced by $7 \%$ and ROI is increased by $8 \%$.

A summary of the result shows that the Capex for the tower is directly proportional to the height of the tower. The operational cost is proportional to the number of mobile network operators sharing the tower or the mobile load on the tower this is the same as the findings in Reference (Akanfe, 2015; Bhardwaj, 2013; Derban, 2011). Hybrid implementation cost is independent of the tower height; implementation will cut operational cost by $32 \%$ this finding is the same in reference (KPMG, 2011), (Bhardwaj, 2013). Comparing the TCO of the $40 \mathrm{~m}$ and $45 \mathrm{~m}$ towers, there is an increase in capital cost of $6 \%$ and $14 \%$ between the $40 \mathrm{~m}$ and $60 \mathrm{~m}$ towers. The NPV for all three towers used are the same. There is a decrease in ROI of $6 \%$ when comparing the $40 \mathrm{~m}$ and 45 $\mathrm{m}$ towers, $16.1 \%$ between the $60 \mathrm{~m}$ and $40 \mathrm{~m}$ tower. The economic performance of the $40 \mathrm{~m}$ tower is better than that of the $45 \mathrm{~m}$ and $60 \mathrm{~m}$ towers. The height of the $40 \mathrm{~m}$ tower is technically economically very good for $5 \mathrm{G}$ deployment; $\mathrm{MNO}$ and tower companies do not have to invest in a $60 \mathrm{~m}$ tower for a $5 \mathrm{G}$ network. 


\subsection{Sensitivity Analysis}

Sensitivity analysis with interest rate and tower height as variables.

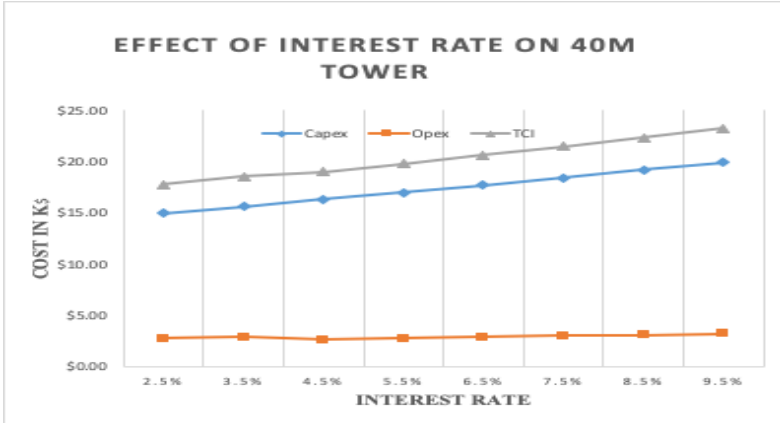

Fig. 1. The effect of interest rate on Capex, Opex, TCO or TCI on a $40 \mathrm{~m}$ tower

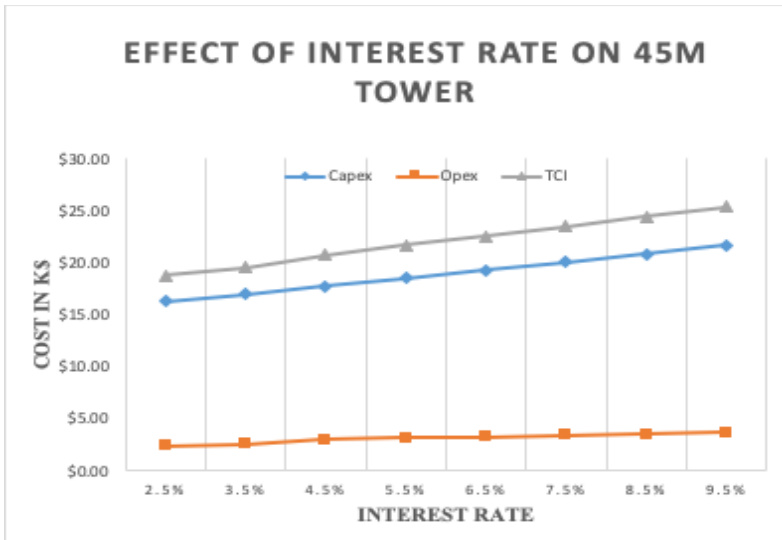

Fig. 2. The effect of interest rate on Capex, Opex, TCO or TCI on a $45 \mathrm{~m}$ tower

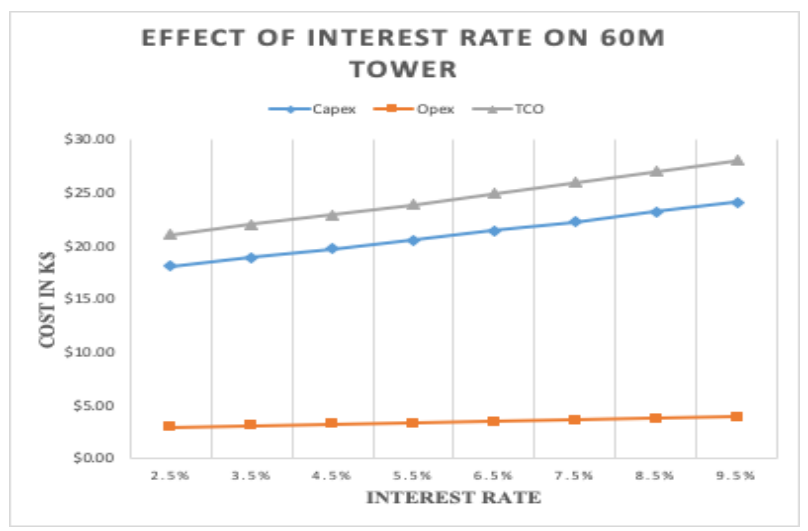

Fig. 3. The effect of interest rate on Capex, Opex, TCO or TCI on a $60 \mathrm{~m}$ tower 
Result discussion. In this section we look at the key parameters that will influence the Capex, Opex, TCO, NPV and ROI. Figure 4 shows that a $40 \mathrm{~m}$ tower with annual repayment TCO is influenced by the interest. At $2.5 \%$, the annual repayment cost of the investment is low and with at least two MNO, the project can be approved. At 3.5\% interest rate, there will be an increase in the entire TCO for the project to $4.2 \%$; at $4.5 \%$ interest rate, there is a $6.4 \%$ increase in the TCO. A $5.5 \%$ interest rate will increase the TCO by $10.5 \%$. At $6.5 \%$ the TCO for the whole project will increase by $14.6 \%$, at an interest rate of $7.5 \%$ the TCO will increase by $18 \%$ and at an interest rate of $8.5 \%$, the TCO will increase by $22.4 \%$. Finally, at $9.5 \%$ the TCO will increase by $26.2 \%$.

Figure 5 shows a $45 \mathrm{~m}$ tower. SA was performed with the interest rate being the variable. When the interest rate is $2.5 \%$, the cost of the investment will enable the best repayment period. The project can be approved when there are only two MNO. When the interest rate moves to $3.5 \%$, the TCO for the entire project will increase by $4.19 \%$, at an interest rate of $4.5 \%$ the TCO will increase by $9.99 \%$, at an interest rate of $5.5 \%$ the TCO will increase by $14.1 \%$, at an interest rate of $6.5 \%$ the TCO will increase by $18.1 \%$. At an interest rate of $7.5 \%$ the TCO will increase by $22 \%$, and at an interest rate of $8.5 \%$ it will increase by $25.9 \%$ and finally at an interest rate of $9.5 \%$, the increase in the TCO will be $29.7 \%$.

Figure 6 represents the SA for a $60 \mathrm{~m}$ tower, where we investigate the effect of the interest rate variation. We started with an interest rate $2.5 \%$. The TCO for the entire project was very low at this interest rate and the cost of capital was cheaper. The TCO for the project would be $4.2 \%$ when the interest rate moved to $3.5 \%$. At $4.5 \%$ interest, the TCO would increase by $8.3 \%$, at a $5.5 \%$ interest rate, one would have a $12.4 \%$ increase in TCO and an interest rate of $6.5 \%$ would result in $16.4 \% \mathrm{TCO}$. At an interest rate of 7.5 the increase in TCO would be $23.3 \%$ and at an interest rate of $8.5 \%$ the TCO would be $24.2 \%$. Finally, at an interest rate of $9.5 \%$, one will have a TCO cost increase to $28 \%$ for the entire project. In summary, it is important to note that the increase in the TCO is also proportional to the tower's height.

Comparing the SA results, the increase in TCO for $40 \mathrm{~m}, 45 \mathrm{~m}$ and $60 \mathrm{~m}$ towers at $7.5 \%, 8.5 \%$ and $9.5 \%$ interest rates are $18 \%, 22.4 \%$, and $26.2 \%$ for a $40 \mathrm{~m}$ tower respectively, $22 \%, 25.9 \%$ and $29.7 \%$ for a $45 \mathrm{~m}$ tower respectively and $23.3 \%, 24.2 \%$ and $28 \%$ for a $60 \mathrm{~m}$ tower. We conclude that the SA outcome shows that MNO and the tower company must take special note of the tower height when deciding to roll out $5 \mathrm{G}$ technology. 
Sensitivity analysis with number of MNO and tower height as variable.

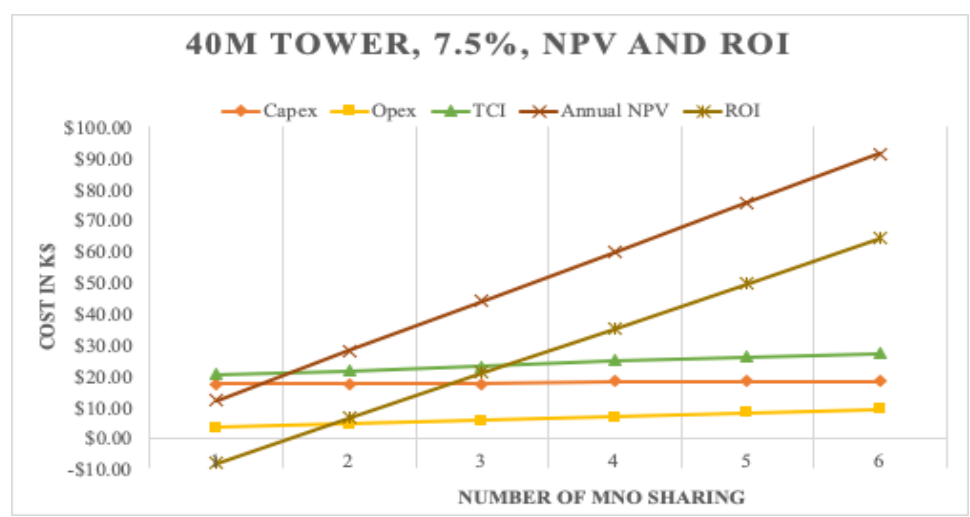

Fig. 4. The Capex, Opex, TCO, NPV and ROI on a $40 \mathrm{~m}$ tower with six MNO

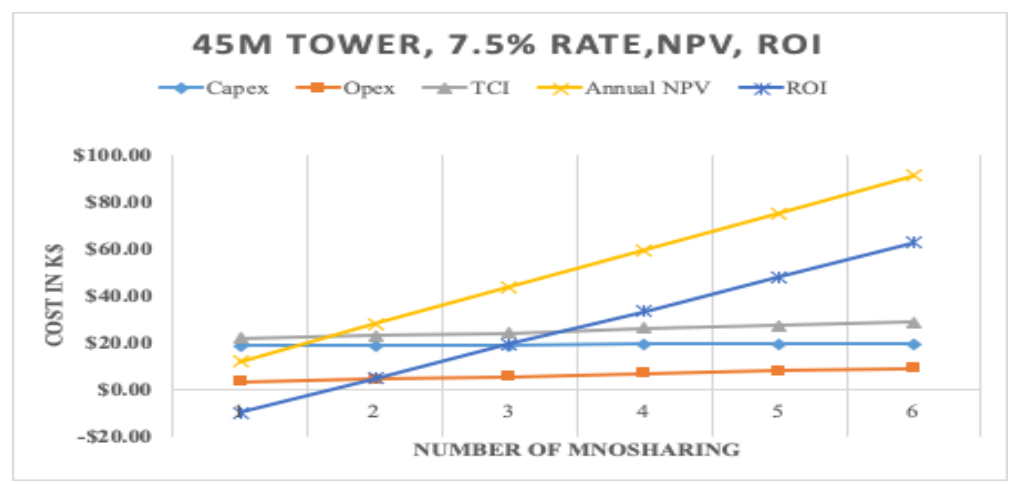

Fig. 5. The Capex, Opex, TCO, NPV and ROI on a $45 \mathrm{~m}$ tower with six MNO

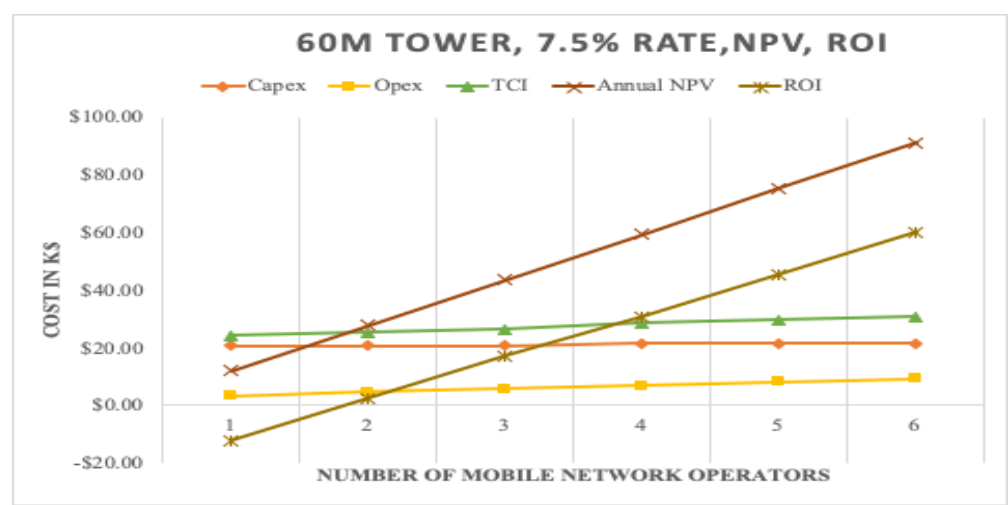

Fig. 6. The Capex, Opex, TCO, NPV and ROI on a $60 \mathrm{~m}$ tower with six MNO 
Figure 4 shows the SA of a $40 \mathrm{~m}$ tower, with a standard interest rate of $7.5 \%$; the Capex, Opex, TCO, NPV and ROI were simulated. The SA simulation shows that the Capex is constant for up to three MNO sharing the tower and will increase by $5 \%$ when sharing increases to four, five and six MNO. The Opex varies based on the load on the sites. The simulation shows that any increase in the number of MNO will increase the Opex by $18.6 \%$ from the initial cost. The result shows that the Opex cost is the main variable cost of the TCO; from the first three MNO, the change in Opex is due to the number of MNO changes to the TCO. The NPV varies based on the number of MNO sharing the tower and the ROI is presented based on the NPV. The ROI is $-41 \%$ for the first MNO sharing the tower and improves to $29 \%$ when a second MNO is added. The third MNO gives $92.2 \%$, the fourth gives $140 \%$, the fifth $191 \%$ and finally when the sixth MNO is added, the return is $236 \%$.

The SA was performed on a $45 \mathrm{~m}$ tower in figure 5 at a $7.5 \%$ interest rate; the Capex, Opex, TCO, NPV and ROI were presented. The result shows that when one, two, three, four, five and six $\mathrm{MNO}$ are sharing the tower, the resulting ROI will be respectively $45 \%, 21 \%, 80 \%, 126 \%, 174 \%$ and $219 \%$. Figure 6 also presents the SA of a $60 \mathrm{~m}$ tower shared by six MNO. The result shows that ROI is $-50.2 \%, 10.1 \%, 80 \%, 126 \% 153 \%$ and $195 \%$ for one, two, three, four, five and six MNO sharing the tower.

In summary, the SA demonstrates that the total cost of ownership is directly proportional to the height and the operational cost is the significant variable Reference (Akanfe, 2015; Bhardwaj, 2013; Derban, 2011). SA also demonstrated that it is not economically viable for an $\mathrm{MNO}$ to own a tower; a single $\mathrm{MNO}$ will take over 10 years to repay the investment. SA shows that the interest rate is essential to the TCO, especially when sharing the tower with two MNO at an interest rate above $7.5 \%$. The SA shows that of the three towers used in this study, the most economic tower infrastructure proposed for $5 \mathrm{G}$ technology deployment is the $40 \mathrm{~m}$ tower. SA demonstrated that the TCO of the $45 \mathrm{~m}$ and $60 \mathrm{~m}$ tower is very high owing to the height of the tower, resulting is poor ROI. The research limitations are due to the simulation data used which are from the tower and MNO companies in Ghana, interest rate, inflation and Taxes were that of Ghana. Simulation result can vary from country to country based on the above variables. Future work could involve consideration of 5G Radio access network (RAN) and Core Network Sharing with edge computing.

\section{Conclusion}

$5 \mathrm{G}$ technology will require a complete overhaul of the telecommunication architecture design, and implementation. There is a need to investigate the technological and economic design and implementation, to determine the most economic approaches. The study proved that the total cost of ownership is directly proportional to the height and the operational cost is the significant variable. SA also demonstrated that it is not economically viable for an $\mathrm{MNO}$ to own a tower; a single $\mathrm{MNO}$ will take over 10 years to repay the investment. SA shows that the interest rate is an essential to the TCO. It is evident that the most economical tower infrastructure proposed for $5 \mathrm{G}$ technology deployment is the $40 \mathrm{~m}$ tower. SA demonstrated that the TCO of the $45 \mathrm{~m}$ and $60 \mathrm{~m}$ towers 
is very high because of the height of the tower, resulting in poor ROI. We conclude that the SA outcome shows that MNO and the tower company must consider the tower height carefully when deciding to roll out $5 \mathrm{G}$ technology.

\section{$7 \quad$ References}

[1] Akanfe, R. (2015). Effect of Network Infrastructure Sharing on Cost Reduction of Network Infrastructure Rollout and Capacity Expansions for Telecoms Operators in Benue State Effect of Network Infrastructure Sharing on Cost Reduction of Network Infrastructure Rollout and Cap, 1(1). https://doi.org/10.1109/iciii.2011.171

[2] Alwraikat, M. (2015). Wireless internet technology to support learning in the university of Jordan: Students voices. International Journal of Interactive Mobile Technologies, 9(3), 410. https://doi.org/10.3991/ijim.v9i3.4031

[3] Bargarai, F. A. M., Abdulazeez, A. M., Tiryaki, V. M., \& Zeebaree, D. Q. (2020). Management of wireless communication systems using artificial intelligence-based software defined radio. International Journal of Interactive Mobile Technologies, 14(13), 107-133. https://doi.org/10.3991/ijim.v14i13.14211

[4] Bhardwaj, S. (2013). Infrastructure Sharing in Telecom Industry: Growth of New Business Models \& their Prospective Trends. ISSN (Print, (2), 2319-5479.

[5] Bouras, C., Kokkalis, S., Kollia, A., \& Papazois, A. (2018a). Techno-economic analysis of MIMO das in 5G. Proceedings of the 201811 th IFIP Wireless and Mobile Networking Conference, WMNC 2018. https://doi.org/10.23919/wmnc.2018.8480920

[6] Bouras, C., Kokkalis, S., Kollia, A., \& Papazois, A. (2018b). Techno-economic comparison of MIMO and DAS cost models in $5 \mathrm{G}$ networks. Wireless Networks, 6, 1-15. https:// doi.org/10.1007/s11276-018-1780-6

[7] Bouras, C., Kokkinos, V., \& Papazois, A. (2014). Financing and Pricing Small Cells in NextGeneration Mobile Networks. https://doi.org/10.1007/978-3-319-13174-0 4

[8] Bouras, C., Kollia, A., \& Papazois, A. (2017). Dense Deployments and DAS in 5G: A Techno-Economic Comparison. Wireless Personal Communications, 94(3), 1777-1797. https://doi.org/10.1007/s11277-016-3711-0

[9] Christos Bouras, Vasileios Kokkinos, Anastasia Kollia, A. P. (2017). Analyzing-SmallCells-and-Distributed-Antenna-Systems-from-Techno-Economic-Perspective.pdf. International Journal of Wireless Networks and Broadband Technologies, 6. https://doi.org/10.40 $\underline{18 / i j w n b t .2017010104}$

[10] Derban, S. (2011). Telecom Infrastructure Sharing as a Strategy for Cost Optimization and Revenue Generation, (June), 1-93. https://doi.org/10.13140/RG.2.1.3569.7043

[11] Eal, D. E. M., \& Boiardi, S. (2014). Radio Planning and Management of Energy-Efficient Wireless, (July).

[12] Elsaadany, A., \& Soliman, M. (2017). Experimental Evaluation of Internet of Things in the Educational Environment.International Journal of Engineering Pedagogy (IJEP), 7(3), 50. https://doi.org/10.3991/ijep.v7i3.7187

[13] Gitman, L. J., \& Zutter, C. j. (2013). Principles of Managerial Finance. In T. O. B. Donna Battista (Ed.) (Thirteenth, pp. 439-462). Angshuman Chakraborty.

[14] Joseph, I. (2013). Statistical tuning of walfisch-bertoni pathloss prediction model based on building and street geometry sensitivity parameters in built-up terrains. American Journal of Physics and Applications, 1(1), 10. https://doi.org/10.11648/j.ajpa.20130101.13

[15] Knoll, T. M., Staufer, M., \& Knoll, T. M. (2012). CAPEX and OPEX evaluation, 1(78). 
[16] KPMG. (2011). Passive Infrastructure Sharing in Telecommunications. KPMG, Cutting Through Complexity, (Oct. 2011). Retrieved from https://www.kpmg.com/BE/en/Issues AndInsights/ArticlesPublications/Documents/Passive-Infrastructure-Sharing-in-Telecomm unications.pdf. https://doi.org/10.1093/ww/9780199540884.013.256294

[17] Levine, T. (2012). Passive infrastructure sharing Why sharing?

[18] McKinsey \& Company. (2018). The road to 5G: The inevitable growth of infrastructure cost McKinsey. McKinsey \& Company, (February), 1-8.

[19] Namisiko, P., Sakwa, M., \& Waweru, M. (2015). Effects of Network Infrastructure sharing Challenges on Open Information Communication Technology Infrastructure Sharing among Mobile Service Providers in Kenya. International Journal of Information Engineering and Electronic Business, 7(3), 11-19. https://doi.org/10.5815/ijieeb.2015.03.02

[20] National Communication Authority. (2017). Quarterly Statistical Bulletin on Communications in Ghana. National Communication Authority, 2(3), 1-36.

[21] NCA Ghana Tests, O. F. S. (2018). National Communications Authority Telcos Sanctioned ghc34 million for failing quality, (6), 4-7.

[22] Norty, E. (2013). National Analytical Report 2010 population and Housing censes. ACCRA.

[23] Osei-owusu, A., \& Henten, A. (2017). Network tower sharing and telecom infrastructure diffusion in Ghana - a Structure-Conduct-Performance approach.

[24] Oughton, E. J., \& Frias, Z. (2018). The cost, coverage and rollout implications of 5G infrastructure in Britain. Telecommunications Policy, 42(8), 636-652. https://doi.org/10.1016/j. telpol.2017.07.009

[25] Smail, G., \& Weijia, J. (2017). Techno-economic analysis and prediction for the deployment of 5G mobile network. Proceedings of the 2017 20th Conference on Innovations in Clouds, Internet and Networks, ICIN 2017, (2015), 9-16. https://doi.org/10.1109/icin.20 17.7899243

[26] Teterin, V., \& Hurley, S. (2014). Optimized network dimensioning and planning for WiMAX technology. Ad Hoc Networks. https://doi.org/10.1016/j.adhoc.2013.08.016

[27] Thabane, L., Mbuagbaw, L., Zhang, S., Samaan, Z., Marcucci, M., Ye, C., Debono, V. B. (2013). A tutorial on sensitivity analyses in clinical trials : the what, why, when and how. https://doi.org/10.1186/1471-2288-13-92

[28] Yunas, S. F., Ansari, W. H., \& Valkama, M. (2016). Technoeconomical Analysis of Macrocell and Femtocell Based HetNet under Different Deployment Constraints. Mobile Information Systems, 2016. https://doi.org/10.1155/2016/6927678

\section{Authors}

Ibrahim Alhassan Gedel and Nnamdi I. Nwulu work at University of Johannesburg, South Africa

Article submitted 2020-07-01. Resubmitted 2020-11-06. Final acceptance 2020-11-07. Final version published as submitted by the authors. 